\title{
Safety and Efficacy Evaluation of Erythrocyte Concentrate Used in Transfusion Therapy in Dogs
}

\author{
Ildikó BARABÁSI, Cristina ȘTEFĂNUȚ, Laurenţ OGNEAN*
}

University of Agricultural Sciences and Veterinary Medicine Cluj-Napoca, 400037, Manastur street, no.3-5, Cluj-Napoca, Romania

*corresponding author: lognean@yahoo.com

Bulletin UASVM Veterinary Medicine 73(2) / 2016,

Print ISSN 1843-5270; Electronic ISSN 1843-5378

DOI:10.15835/buasvmcn-vm: 12260

\begin{abstract}
The study followed the packed cell volume levels 6 hours after transfusion and the hematology parameters through a complete blood count performed 5 days after transfusion therapy. Patients have been monitored throughout their stay in the clinic for any signs of transfusion related adverse reactions. Blood tests were performed with ADIVA hematological analyzer; the 6 hour post-transfusion packed cell volume was determined by a microhematocrit measurement. On admission every patient received a routine blood test that included 40 hematological parameters and 21 biochemical parameters. In addition, a detailed examination of the blood smears was also performed by the ADIVA hematological analyzer with 26 parameters that mostly referred to red blood cell and white blood cell morphology. Blood typing was done using the RapidVet quick test kit. Patients received only type specific blood and to limit transfusion reaction occurrences, in addition, a crossmatch test was performed before every transfusion. Statistical analysis reveal that the total red blood cell count underwent very significant changes $(\mathrm{p}=0.0052)$ as well as the hemoglobin $(\mathrm{p}=0.0085)$. The packed cell volume had an extremely significant evolution $(p=0.0002)$. The erythrocyte concentrate can be used safely even in critically ill or immune-suppressed patients and even in patients with an exaggerated immune response. A clear dosage of this blood product has not been set yet, every administration has to be tailored to the patient's needs.
\end{abstract}

Keywords: dogs, erythrocyte concentrate, packed cell volume, immune-mediated hemolytic anemia, transfusion therapy

\section{INTRODUCTION}

The purpose of this study has been the evaluation of the immediate and long term therapeutical efficacy of erythrocyte concentrate in dogs with different types of anemia. These objectives have been pursued by measuring the packed cell volume level 6 hours after the transfusion therapy has been discontinued and by performing a complete blood count 5 days posttransfusion therapy. We also clinically monitored the patients for any signs of transfusion related adverse reactions.

\section{MATERIAL AND METHOD}

This research took place in the Small Animal Clinic of Internal Medicine Department of JustusLiebing University in Giessen, Germany. The study lasted for 6 months, between February and August of 2014. During this time 18 dogs received transfusion therapy with erythrocyte concentrate. From this patient pool $44.44 \%(n=8)$ were female and $55.55 \%(n=10)$ male. Mean age of the patients has been 6.5 years, with the youngest patient being 1 year old and the oldest 11 years old. The patients have been of quite varied breeds: 3 common breeds, 2 Cane Corso Italiano, 2 Labrador Retrievers, 1 Border Collie, 1 Shetland Shepherd, 1 Bearded Collie, 1 Miniature Pinscher, 1 Spitz, 1 Havanese Bichon, 1 Australian Shepherd, 1 Doberman Pinscher, 1 Dachshund, 1 Cocker Spaniel and 1 Belgian Shepherd.

Blood tests have been made with ADIVA hematologicalanalyzer; the6hourpost-transfusion packed cell volume has been determined by per- 
forming a micro packed cell volume. Every patient taken into this study has been transferred to the clinics Intensive Care Unit where they were permanently monitored. On admission every patient received a routine blood test that included 40 hematological parameters and 21 biochemical parameters. In addition, a detailed examination of the blood smears has been also performed by the ADIVA hematological analyzer with 26 parameters that mostly referred to red blood cell and white blood cell morphology.

All erythrocyte concentrate units were prepared in the clinic. This way the obtained erythrocyte concentrate units were almost identical, with a packed cell volume level of about $70 \%$. All units were stored in a refrigerator used only for blood product storage that was monitored daily by a technician for a constant adequate temperature. None of the blood units have been stored for longer than 6 days. Every patient has been blood typed for DEA 1.1 blood type, using the RapidVet quick test kit. Patients received only type specific blood and to limit transfusion reaction occurrences, in addition, a crossmatch test has been performed before every transfusion. This crossmatch test served another purpose as well, besides verifying patientdonor compatibility; a positive auto-agglutination test provided an additional proof for the immunemediated hemolytic anemia diagnosis.

Eighteen patients were included in our study. The causes of anemia encountered in this patient group were not been very versatile, mostly because the study was performed in a referral clinic. Most patients (61.11\%; no=11) were diagnosed with idiopathic immune-mediated hemolytic anemia. Of these 11 patients only in one was the immune-mediated anemia linked later to a lymphoma. From the rest of the group 2 patients $(11.11 \%)$ were diagnosed with rodenticide poisoning, 1 (5.55\%) with babesiosis, 1 with a hemangyosarcoma, 1 with adenocarcinoma and septic peritonitis due to complications that occurred after surgery, 1 idiopathic liver damage and 1 with hypothyroidism. The patients in this study received a total of 30 blood transfusions (a mean of 1.66). The largest number of transfusions given to one patient was 4 , all in the first 5 days of admission. Mean dose of administered erythrocyte concentrate has been $11.46 \mathrm{ml} / \mathrm{kg}$, with a minimal dose of $3.4 \mathrm{ml} / \mathrm{kg}$ and a maximum dose of 24.7 $\mathrm{ml} / \mathrm{kg}$. Mean transfusion rate has been $21.86 \mathrm{ml} /$ $\mathrm{kg} / \mathrm{h}$, with a minimum speed of $6 \mathrm{ml} / \mathrm{kg} / \mathrm{h}$ and a maximum speed of $45 \mathrm{ml} / \mathrm{kg} / \mathrm{h}$.

Research concerning the long term therapeutical efficacy (5 days post-transfusion) of erythrocyte concentrate used in transfusion therapy has been conducted upon 13 of the 18 patients of this study. Of these 5 patients excluded from the second phase of the study, 4 were released from the clinic in less than 5 days. One patient suffered from an extremely severe form of immune-mediated hemolytic anemia and received 4 transfusions in its first 5 days of admission. From the 13 patients that have been included into the long term therapeutical efficacy study of erythrocyte concentrate, 3 have received 2 transfusions in less than 24 hours apart. The rest of the patients received one transfusion each.

Statistical analysis of the transfusion therapy efficacy has been performed with GraphPadInStat 3.0 statistical program and the graphical depiction in form of a box-plot of the obtained results has been made using the Origin 8.5. graphics program.

\section{RESULTS AND DISSCUTIONS}

In the present study we have followed the evolution of the total white blood cell level, the neutrophil level, lymphocyte numbers, the total red blood cell count, the packed cell volume level, platelet number, the total number of reticulocytes and the spherocyte percentage from the day of admission (T0) up to the $5^{\text {th }}$ day (T5) after the last administered transfusion therapy with erythrocyte concentrate. In the case of those patients that needed multiple transfusions, T5 has been considered the $5^{\text {th }}$ day after the last administered transfusion therapy. The decision of starting a transfusion therapy has been made by the attending physician of each patient. Administered doses had been given according to the results obtained from the following equation:

Transfused volume $=$ (desired Ht- patient Ht/ donor $\mathrm{Ht}$ ) $\mathrm{x}$ kg b.w x 90

Short and his team performed in 2012 a comparative study of equations designed to calculate blood product amount that should be given to a patient. According to their results, this equation is the most accurate in calculating the needed blood product dose. 
The desired packed cell volume level that the patient should have reached after the transfusion therapy has been set by the attending physician of each patient. Alongside the transfusion therapy, the patients have been treated according to the their pathology, but none received any kind of intravenous or other type of treatment as long as the transfusion therapy has been administered. Of the 18 patients that have been monitored for the packed cell volume level changes at 6 hours posttransfusion therapy, only in one have we observed transfusion related adverse reactions represented by vomiting, pyrexia, melena, hemoglobinuria and hemoglobinemia. This patient suffered from a very severe form of immune-mediated hemolytic anemia and presented transfusion related adverse reactions after every transfusion therapy.

A total of 30 transfusions have been administered to the 18 patients taken into the study of the immediate therapeutic efficacy of erythrocyte concentrate in dogs. Patient-donor blood compatibility was determined by blood typing of both individuals and a crossmatch test performed before every transfusion therapy. Of these 30 transfusions $6(20 \%)$ reached exactly the desired packed cell volume level at 6 hours posttransfusion, used in the above presented equation. In 2 occasions $(6.66 \%)$, both transfusion given to patients with immune-mediated hemolytic anemia, we have observed a higher than expected level of the packed cell volume (of $6 \%$ and $12 \%$, respectively) at 6 hours after transfusion. The other 22 administered transfusion therapies (73.33\%) did not produce the calculated augmentation upon the packed cell volume level at 6 hours after transfusion.

Excluding the 4 transfusions given to the patient with the very severe form of immune-mediated hemolytic anemia, not one of the transfusions produced any adverse effects. We did not find any proof of a potential intravascular or extravascular hemolytic reaction in any other patient. The mean difference observed between the desired packed cell volume level used in the equation and the actual packed cell volume level reached after 6 hours post-transfusion therapy has been $3.59 \%$, with a minimal difference of $2 \%$ and a maximum difference of $12 \%$. The statistical analysis revealed an extremely significant $(\mathrm{p}<0.0001)$ increase of the packed cell volume level changes observed at 6 hours after transfusion.
Our study regarding long term therapeutical efficacy included only 13 of the initial 18 patients for reasons mentioned above. Each of these 13 patients survived until discharge. This study focused upon hematological changes observed between admission day (T0) and the $5^{\text {th }}$ day after the transfusion therapy with erythrocyte concentrate has been discontinued (T5). Table 1 depicts the hematological parameters on admission day that we followed through this study. We have observed major changes in the evolution of every hematological parameter that we followed. The statistical analysis conducted on the obtained results reveal that the total red blood cell count underwent very significant changes $(p=0.0052)$; the hemoglobin suffered as well a very significant change $(p=0.0085)$. Of all the hematological parameters that we studied, the one with the most significant evolution has been the packed cell volume. This suffered a statistically extremely significant evolution $(\mathrm{p}=0.0002)$.

As far as the other hematological parameters are concerned, none underwent statistically significant evolutions from T0 until T5. After they have been discharged all patients have had outpatient treatments continued at home. In addition to this, they have been called in weekly for follow-up examinations in the first month.

Patients, who could not come to the clinic for the scheduled follow-up examinations, performed the necessary check-ups and blood tests at a local veterinarian office that kept in touch and consulted the next treatment steps with the cases initial physician from the clinic. According to the patient's evolution, these follow-up examinations decreased from weekly to monthly visits. Every case has been followed through until the treatment could be discontinued. From these periodical follow-up examinations, we have learned that none of the patients included in this study manifested any delayed transfusion related reactions.

Only one patient suffered a relapse of a severe case of immune-mediated hemolytic anemia and came back to the clinic in a critical state. The owners refused treatment and the patient was consequently euthanized. Transfusion therapy using erythrocyte concentrate has been proven to be well tolerated by dogs. Even severally ill patients did not manifest any adverse reactions to this treatment. The few reactions that we have 
observed were in fact induced by the patient's primary illness, the hemolytic anemia.

Research conducted upon the packed cell volume level changes pre- and 6 hours posttransfusion, revealed a small percentage of cases in which the desired packed cell volume rise has been achieved using the blood product dose obtained using the equation. Our study showed a mean difference between the desired packed cell volume level used in the equation and the obtained one at 6 hours after transfusion to be $3.59 \%$. This small difference still allows us to stipulate the efficacy of the transfusion therapy.

However, a revision of the used equation is needed since in most of the administered transfusions there has been an absence of any transfusion related adverse reactions, but the desires packed cell volume level has not been achieved. Also an important fact that must be taken into account is that the transfusion treatment was initiated shortly after the patient has been admitted. Most of the patients that have been taken into this study were diagnosed with an immune-mediated pathology in which the body destroys its own red blood cells. The treatment for the immune-mediated hemolytic anemia has been started in the same day as the transfusion therapy. The failure to achieve the calculated packed cell volume at 6 hours post-transfusion involves also the pathological process of the patient. Taking into account the packed red cell level evolution from the day of admission and 5 days after the transfusion therapy has been discontinued, it can be stated that this therapy has reached the desired effect. In the $5^{\text {th }}$ day after transfusion an increase in the packed cell volume level can be observed (Fig.1.).

The same positive effect can be seen in the total number of red blood cells. We were able to observe an increase of this parameter in every patient included in this study (Fig. 2.).

Similar data was found other veterinary hematogists (Gibson, 2007; Helm et al., 2010, Kisielewicz et al., 2014), who made some indications on dosage and good practice protocols following their research. Also Ognean (2015) his and collaborators have reached similar conclusions in a study focused on transfused dogs. Next to the packed cell volume level and the red blood cell count, hemoglobin is the third hematological parameter used to evaluate the severity of the anemia and bloods oxygen carrying capacity

Tab. 1. Hematological parametres on admission day (T0)

\begin{tabular}{|c|c|c|c|c|c|c|c|c|c|}
\hline No. & $\begin{array}{c}\text { WBC } \\
10^{9} / 1 \\
\end{array}$ & $\begin{array}{c}N \\
10^{9} / 1 \\
\end{array}$ & $\begin{array}{c}\mathrm{L} \\
10^{9} / 1 \\
\end{array}$ & $\begin{array}{c}\text { PLT } \\
10^{9} / 1 \\
\end{array}$ & $\begin{array}{c}\text { RBC } \\
10^{12} / 1 \\
\end{array}$ & $\begin{array}{l}\mathrm{Ht} \\
\mathrm{l} / \mathrm{l} \\
\end{array}$ & $\begin{array}{c}\mathrm{Hb} \\
\mathrm{mmol} / \mathrm{l}\end{array}$ & $\begin{array}{c}\text { Reti } \\
10^{9} / 1 \\
\end{array}$ & $\begin{array}{c}\text { Spher } \\
\%\end{array}$ \\
\hline 1. & 42.0 & 7.25 & 29.67 & 958 & 1.33 & 0.14 & 3.4 & 668.5 & 3 \\
\hline 2. & 17.08 & 10.90 & 4.82 & 183 & 1.80 & 0.14 & 3.9 & 82.90 & 2 \\
\hline 3. & 73.04 & 38.53 & 26.75 & 359 & 1.25 & 0.13 & 3.2 & 605.5 & 2 \\
\hline 4. & 26.59 & 18.28 & 6.51 & 563 & 1.57 & 0.18 & 2.8 & 530.2 & 3 \\
\hline 5. & 18.03 & 11.03 & 1.98 & 573 & 4.99 & 0.26 & 8.3 & 156.7 & 1 \\
\hline 6. & 8.40 & 5.57 & 2.19 & 16 & 3.48 & 0.23 & 4.7 & 5.10 & 3 \\
\hline 7. & 34.63 & 26.82 & 5.32 & 75 & 2.11 & 0.15 & 3.0 & 231.1 & 2 \\
\hline 8. & 19.53 & 9.53 & 8.19 & 174 & 1.35 & 0.10 & 2.1 & 85.70 & 3 \\
\hline 9. & 17.24 & 14.38 & 1.14 & 70 & 2.52 & 0.15 & 5.2 & 126.3 & 2 \\
\hline 10. & 12.96 & 7.91 & 3.51 & 185 & 1.96 & 0.15 & 4.7 & 79.2 & 3 \\
\hline 11. & 6.44 & 2.65 & 3.19 & 440 & 1.85 & 0.12 & 2.8 & 10.0 & 0 \\
\hline 12. & 8.62 & 6.48 & 1.40 & 81 & 2.22 & 0.17 & 2.9 & 438.3 & 1 \\
\hline 13. & 32.3 & 19.92 & 6.38 & 156 & 2.03 & 0.15 & 3.1 & 171.1 & 2 \\
\hline Mean & 24.37 & 13.7 & 7.77 & 294.8 & 2.18 & 0.15 & 3.85 & 245.4 & 2.1 \\
\hline StD & 18.2 & 9.98 & 9.33 & 273.1 & 1.02 & 0.04 & 1.61 & 232.2 & 0.95 \\
\hline Min. & 6.44 & 2.65 & 1.14 & 16.0 & 1.25 & 0.10 & 2.1 & 5.1 & 0 \\
\hline Max. & 73.04 & 38.53 & 29.67 & 958 & 4.99 & 0.13 & 8.3 & 668.5 & 3 \\
\hline Ref . val. & $6.0-17.0$ & $2.78-8.73$ & $0.72-4.71$ & $150-500$ & $5.5-8.5$ & $0.39-0.56$ & $8.06-12.21$ & $0-60$ & $<4 \%$ \\
\hline
\end{tabular}


(Callan, 2010). Hemoglobin levels have risen in every patient taken into study in the 5 days after the transfusion therapy has been discontinued (Fig.3).

The total number of white blood cells, neutrophils and lymphocytes, has been mostly influenced by the patient's pathology. The total number of platelets has had a rising tendency between the day of admission and the $5^{\text {th }}$ day post-transfusion, their value being outside of the physiological reference range in only 4 of the patients in the $5^{\text {th }}$ day after transfusion. The majority of the 13 patients taken into the long term efficacy study of erythrocyte concentrate have reached a point in the $5^{\text {th }}$ day after transfusion therapy in which they were no longer considered in danger of tissue hypoxia.

Two patients remained with low red blood cell number and packed cell volume level, but an increase of the hematological parameters could

Tab.2. Hematological parameters on the $5^{\text {th }}$ day post-transfusion

\begin{tabular}{|c|c|c|c|c|c|c|c|c|c|}
\hline No. & $\begin{array}{l}\text { WBC } \\
10^{9} / 1\end{array}$ & $\begin{array}{c}\mathrm{N} \\
10^{9} / 1\end{array}$ & $\begin{array}{c}\mathrm{L} \\
10^{9} / \mathrm{l}\end{array}$ & $\begin{array}{l}\text { PLT } \\
10^{9} / 1\end{array}$ & $\begin{array}{c}\mathrm{RBC} \\
10^{12} / \mathrm{l}\end{array}$ & $\begin{array}{l}\mathrm{Ht} \\
\mathrm{l} / \mathrm{l}\end{array}$ & $\begin{array}{c}\mathrm{Hb} \\
\mathrm{mmol} / \mathrm{l}\end{array}$ & $\begin{array}{c}\text { Reti } \\
10^{9} / 1\end{array}$ & $\begin{array}{c}\text { Spher } \\
\%\end{array}$ \\
\hline 1. & 19.59 & 7.61 & 10.30 & 901 & 3.81 & 0.34 & 6.3 & 724.4 & 10 \\
\hline 2. & 35.68 & 27.48 & 4.39 & 18.51 & 2.37 & 0.18 & 5.5 & 206.50 & 0 \\
\hline 3. & 43.9 & 26.43 & 12.21 & 538 & 3.17 & 0.29 & 4.8 & 974.5 & 20 \\
\hline 4. & 30.33 & 23.53 & 3.06 & 905 & 2.69 & 0.26 & 4.5 & 440.7 & 3 \\
\hline 5. & 29.86 & 27.57 & 1.17 & 832 & 4.26 & 0.25 & 4.8 & 53.5 & 1 \\
\hline 6. & 10.22 & 7.34 & 2.34 & 19 & 4.41 & 0.30 & 6.2 & 7.10 & 1 \\
\hline 7. & 10.56 & 6.92 & 2.90 & 129 & 7.00 & 0.50 & 10.1 & 507.10 & 10 \\
\hline 8. & 10.90 & 3.45 & 6.54 & 292 & 4.01 & 0.29 & 5.5 & 363.90 & 5 \\
\hline 9. & 12.02 & 8.45 & 2.37 & 136 & 4.60 & 0.33 & 6.3 & 227.80 & 4 \\
\hline 10. & 10.05 & 7.75 & 1.69 & 464 & 3.08 & 0.25 & 4.4 & 108.0 & 7 \\
\hline 11. & 7.53 & 3.93 & 2.80 & 301 & 3.39 & 0.24 & 4.8 & 13.70 & 0 \\
\hline 12. & 2.76 & 1.18 & 1.02 & 207 & 3.47 & 0.26 & 4.8 & 42.20 & 0 \\
\hline 13. & 76.95 & 39.11 & 26.86 & 110 & 1.18 & 0.12 & 4.9 & 275.70 & 7 \\
\hline Mean & 23.1 & 14.67 & 5.97 & 373.2 & 3.64 & 0.27 & 5.6 & 303.4 & 5.7 \\
\hline StD & 20.4 & 12.3 & 7.17 & 327.0 & 1.37 & 0.08 & 1.5 & 295.5 & 5.23 \\
\hline Min. & 2.76 & 1.18 & 1.02 & 18.51 & 1.18 & 0.12 & 4.4 & 7.1 & 0 \\
\hline Max. & 76.95 & 39.11 & 26.86 & 905 & 7.00 & 0.22 & 10.1 & 974.5 & 20 \\
\hline Ref . val. & $6.0-17.0$ & $2.78-8.73$ & $0.72-4.71$ & $150-500$ & $5.5-8.5$ & $\begin{array}{c}0.39- \\
0.56\end{array}$ & $8.06-12.21$ & $0-60$ & $<4 \%$ \\
\hline
\end{tabular}

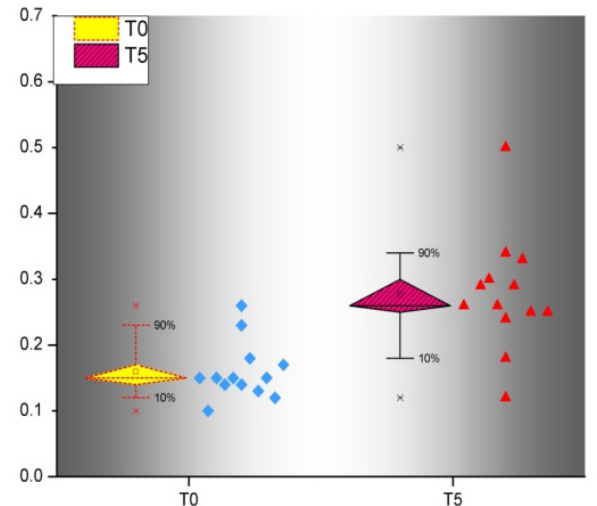

Fig.1. Packed cell volume level evolution between day of admission and the $5^{\text {th }}$ day post-transfusion

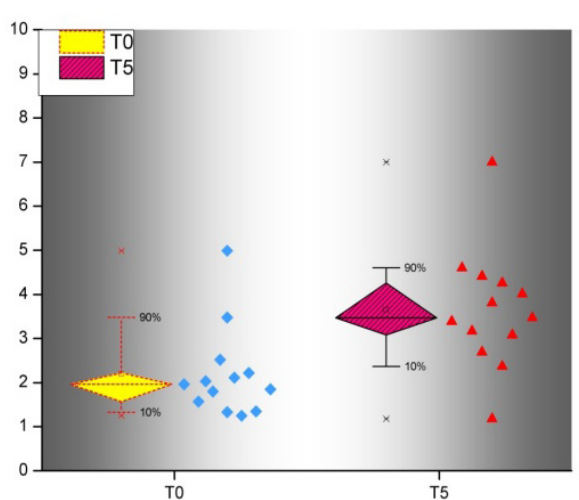

Fig.2. Red blood cell count from admission day and the $5^{\text {th }}$ day post-transfusion 


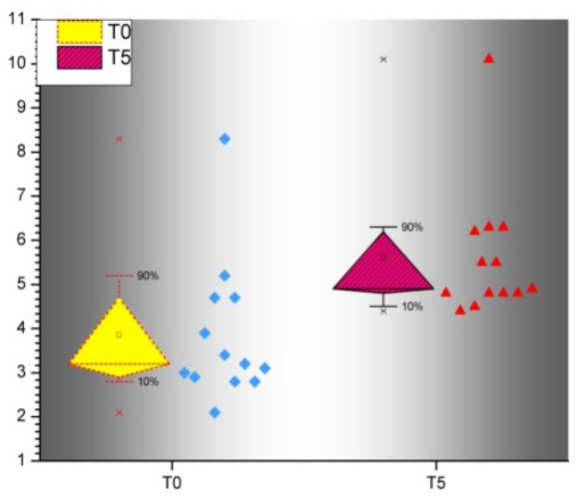

Fig.3. Hemoglobin amount evolution from day of admission and the $5^{\text {th }}$ day post-transfusion

be seen anyway in the $5^{\text {th }}$ day post-transfusion comparing to admission day. Some of the studied values have been increased and influenced by the body's own compensatory mechanisms as well that involve an increased production and release of reticulocytes.

These are precursor cells that the body produces in a much faster rate and greater amount to compensate the lack of red blood cells in case of an anemia caused of no matter what. This response of the bone-marrow can be seen in 3 to 5 days after clinical signs of anemia are visible. A greater number of reticulocytes have been observed on admission in comparison to the $5^{\text {th }}$ day after transfusion therapy in 12 of the 13 patients that took part of the study. Production of these cells decreases only if the patient is no longer anemic or if the cell production capacity of the bonemarrow has been suppressed or compromised.

\section{CONCLUSIONS}

The erythrocyte concentrate can be used safely even in critically ill patients, immune-suppressed, or in case of an exaggerated immune response. A clear dosage of this blood product has not been set yet; every administration has to be tailored to the patient's needs. The equation used to calculate administered dose, failed to give an amount that would get the desired increase in packed cell volume levels at six hours post-transfusion. However, it must be taken into account that most patients in this study have been diagnosed with immunemediated hemolytic anemia that could have contributed to the failure of reaching the calculated packed cell volume level.

\section{REFFERENCES}

1. Callan MB (2010). Red blood cell transfusion in dogs and cats, In: Schlam's Veterinatry Hematology, Ed. Douglass J. Weiss, Jane K. Wardrop, ed John Wiley \&Sons, chap. 95:738-743.

2. Gibson G (2007). Transfusion medicine, In: Canine and feline emergency and critical care, Ed., Lesley G. King, Amanda Boag, ed. BSAVA, 2nd ed, 14:215-227.

3. Helm J, Knottenbelt C (2010). Blood transfusion in dogs and cats. In Practice 32:184-189.

4. Kisielewicz C, Self IA (2014). Canine and feline blood transfusions: controversies and recent advances in administration practices. Veterinary Anaesthesia and Analgesia 41: 233-242.

5. Ognean L, Chiurciu V, Ștefănuț C, Oana L, Morar I, Barabási I (2015). Transfusion Triggers and Therapeutic Efficacy in a Group of Dogs That Underwent Whole Blood Therapy. Agriculture and Agricultural Science Procedia 6:363-369.

6. Short JL, Diehl S, Seshadri R, Serrano S (2012). Accuracy of formulas used to predict post-transfusion packed cell volume rise in anemic dogs, Journal of Veterinary Emergency and Critical Care 22: 428-434. 